\title{
An Exploration of 'Fitspiration' content on YouTube and its impacts on consumers
}

\author{
Miss Priyanjali Ratwatte ${ }^{1}$, and Dr Emily Mattacola ${ }^{1^{*}}$ \\ ${ }^{1}$ University of Buckingham \\ *Corresponding author information: Dr Emily Mattacola, School of Psychology \& \\ Wellbeing, University of Buckingham, Hunter Street, Buckingham, UK MK18 $1 \mathrm{EG}$ (e- \\ mail: emily.mattacola@buckingham.ac.uk).
}

\section{Competing interests}

The authors received no financial support for the research, authorship, and/or publication of this article.

\section{Abstract}

The 'Fitspiration' movement may endorse problematic body image and behaviour.

This study aims to expand the understanding of 'fitspiration' by examining its presence on YouTube. Analysis was conducted in accordance with Tiggeman \& Zaccardo (2015) and Santarossa et al. (2016). Thematic analysis of videos revealed three themes; 'Fitness and beauty', 'Trust me-l'm a YouTuber', and 'Health for the right reasons'. Thematic analysis of comments revealed themes 'YouTube fitness community', 'Body appearance dissatisfaction,' and 'YouTuber fitness role models'. Fitness YouTubers were found to promote unhealthy behaviours to achieve fitness, and commenters expressed belief in and replication of their advice.

\section{Keywords}

Body image; Social networking; Fitspiration; Media; Fitness; YouTube 


\section{Introduction}

The impact of beauty ideals presented in traditional media is well established (Benton and Karazsia, 2015; Eisenberg et al., 2017; Eyal and Te'eni-Harari, 2013; Galioto and Crowther, 2013; Harrison, 2000, 2003; Hausenblas et al., 2013; Robinson et al., 2017). Females are exposed to a thin body ideal (D'Alessandro and Chitty, 2011), whilst the masculine ideal has been cultivated through muscular body types (Cafri et al., 2005). The impact of these beauty standards is believed to operate via positive biases (Benton and Karazsia, 2015; Robinson et al., 2017), social comparison (Dittmar and Howard, 2004; Myers and Crowther, 2009; Tiggemann and Slater, 2004), and Social Learning Theory (Bandura, 1978), resulting in body dissatisfaction and the onset of damaging health behaviours in pursuit of unattainable beauty ideals (Cramblitt and Pritchard, 2013; Flament et al., 2012; Knobloch-Westerwick, 2015).

The translation of these beauty ideals to the internet has made them more accessible, dynamic, and elaborate (Lehman-Wilzig and Cohen-Avigdor, 2004). Social media is defined as any website that allows social interaction. This broad definition includes including social networking sites, such as Facebook and Instagram; gaming sites, such as World of Warcraft, video-sharing sites, such as YouTube; and blogging (O’Keeffe and Clarke-Pearson, 2011). Social media enables sharing and greater accessibility of beauty ideals (Fardouly and Vartanian, 2016), thought to have unfavourable consequences for health behaviour (Perloff, 2014). Social media use has been found to positively relate to internalisation of beauty ideals regardless of gender, and is positively associated with body image concerns and disordered eating (Holland and Tiggemann, 2016). Therefore, consumption of beauty ideals via social media leads to similar body dissatisfaction and detrimental 
health behaviours as traditional media. Emerging research on social media use and body dissatisfaction has stressed the importance of extending body dissatisfaction literature to include social media due to findings of consequent eating disorder symptomology and poor health outcomes (Cohen and Blaszczynski, 2015; McLean et al., 2015; Sidani et al., 2016).

A focus of research relating to beauty ideals via social media has been the 'thinspiration' (a contraction of 'thin' and 'inspiration') movement (Boepple and Thompson, 2016). 'Thinspiration' is the endorsement and promotion of content relating to eating disorders, weight loss, and images of extremely thin bodies identified by \#thinspiration and \#thinspo (Boepple and Thompson, 2016). Thinspiration promotes a skeletal body as a beauty ideal (Ghaznavi and Taylor, 2015). Content analyses of \#thinspiration across social media platforms such as Tumblr and Instagram revealed that the majority of images contained extremely thin women, with accompanying text including themes of food restriction, purging, overexercising and fat phobia (Chancellor et al., 2016; Wick and Harriger, 2018). Over time, the negative influence of thinspiration on health was recognised and led to the eventual ban of \#thinspiration on Tumblr and Instagram (Judkis, 2012). In its wake, a new aesthetic emerged on social media; 'fitspiration' (Tiggemann and Zaccardo, 2015, 2016).

Fitspiration is a contraction of the words fitness and inspiration, and has a social media presence which seeks to act as a source of motivation for exercise and healthy lifestyles (Abena, 2013). Previous literature has defined fitspiration content as that which claims to promote health and wellbeing through images depicting healthy eating, exercise, self-care, strength, and empowerment, over thinness and weight loss (Tiggemann and Zaccardo, 2015). Although fitspiration outwardly 
embodies a message of health, recent investigations suggest that some thinspiration content has migrated to the new hashtag. 'Fitspiration' content is aligned with the 'fit ideal', characterised by images of thin, toned females, and hyper-muscular males, and equates fitness with thinness (Tiggemann and Zaccardo, 2016), with some content idealising a very thin body type reminiscent of thinspiration (Talbot et al., 2017). Therefore, fitspiration may still popularise goals related to unrealistic beauty ideals, and encourage behaviour change to fulfil aesthetic-oriented, rather than health-related, goals. Experimentally, such images have been found to be related to increased body dissatisfaction, low mood, and decreased appearance-related selfesteem (Tiggemann and Zaccardo, 2015), and poorer self-compassion (Slater et al., 2017). As a result of fitspiration's message of health promotion, consumers of fitspiration may enact unhealthy behaviours sourced from fitspiration content, believing their actions to be health positive (Tiggemann and Zaccardo, 2016). Indeed, analyses of \#fitspiration images on Instagram have uncovered content promoting a restrictive diet and over-exercising (Santarossa et al., 2016; Tiggemann and Zaccardo, 2016). Therefore, fitspiration has demonstrated its potential to be detrimental to health, and due to its increasing popularity across social media, more research is necessary to assess its content and impact.

YouTube is a video-sharing social media platform with 1.8 billion users who rate, share, and comment on user-generated video content (Khan, 2017). Primarily a media sharing site, YouTube incorporated social networking elements in response to the exponential growth in social media and user-generated online content, and is now classed as a social networking site (Boyd and Ellison, 2007). YouTube's popularity and influence can be credited to its unique host-user relationship (Chau, 2010). As well as consuming content, users are able to create their own channels to 
post videos and become hosts. In this way, users are able not only to view and interact with posts, but also to create, connect, collaborate, and circulate content in a way which is unique in social media (Chau, 2010). Users who host video channels are known as 'YouTubers'. Users viewing YouTuber content are able to interact with hosts and each other through comment threads on each video. Users can subscribe to YouTube channels, enabling them to be notified whenever new content is shared by the host (Tolson, 2010). This combination of video-based content and user interaction means that YouTube is able to present fitspiration content in a uniquely engaging form (Hanson, 2009).

\section{Aim and Objective}

There are currently over 9 million fitness and health channels on the website (YouTube, 2018). Despite this, to the authors' knowledge, no research has investigated the content of fitspiration on YouTube or its interaction with viewers. Therefore, the current study aims to explore fitspiration content on YouTube in an attempt to identify the nature of the messages being endorsed, and the ways in which viewers interpret and engage with this content. The research questions are:

1. What health, fitness and appearance messages are being promoted by fitspiration content on YouTube?

2. How do viewers perceive and interact with fitspiration content on YouTube?

\section{Methodology \\ Design}

The study utilised a three-part qualitative design; thematic analysis of transcripts of YouTube video audio, content analysis of the imagery in these videos, and thematic analysis of corresponding user comments. 


\section{Video Selection}

To produce data comparable to previous literature looking at image content (Boepple and Thompson, 2016; Santarossa et al., 2016; Tiggemann and Zaccardo, 2016), the ten YouTube fitspiration channels with the highest numbers of subscribers were identified. From each channel, the three videos with the highest number of views from their available videos were selected for analysis. Images were obtained by taking a screenshot of each scene in each video. The videos yielded a varied number of images, producing 184 in total from the 30 videos. Video audio ranged in length from 7 to 33 minutes.

Of the comments, the ten highest-rated comments (based on the ratio of user likes to user dislikes), including comment threads, were selected from each selected video. In line with the definition of fitspiration presented by Tiggemann and Zaccardo (2015), to be included, the channel and video were required to contain health and fitness content and the words 'fitspiration', 'fitspo', 'fitness', or 'fit'. Channels and videos that only contained instructional fitness or cooking videos were excluded, to ensure that those seeking to "inspire" viewers were included. The channels that were selected are described in Table 1.

$\ll$ <INSERT TABLE 1 HERE >>

\section{Procedure}

Search terms were entered into the YouTube search bar to reveal fitness channels. The search terms were 'fit inspiration', 'fitness lifestyle', 'fit life', 'fit', 'fitness' and 'fitness and health'. Filters were applied to sort results to only show videos posted by channels, and to display results by descending view count. Channels with the highest number of subscribers were reviewed according to the aforementioned inclusion/exclusion criteria, with the ten most subscribed channels selected. 


\section{Analytic Framework}

\section{Content Analysis}

Content analysis replicated the coding structure used by Tiggemann and Zaccardo (2016) focusing on the body shape, the activities being engaged in, and objectification in images.

First, images were coded according to one of three categories; people, food, or other. Images of people were further coded on the basis of the number and gender of people in the image, their body shape (according to adiposity and muscularity), and the activity they were engaged in. Images of food were coded as healthy or unhealthy.

A second coder coded all of the images to ensure validity and reliability of the image codes. Coding reliability was high with $94 \%$ agreement.

\section{Thematic analysis}

The transcribed video audio and text comments were analysed using an inductive thematic analysis, as per the six-phase systematic process outlined by Braun \& Clarke (2006). After becoming familiar with the data corpus, initial codes were generated. Codes were then sorted into candidate themes and subthemes, which were then reviewed for their quality, internal homogeneity, and external heterogeneity. The remaining themes were then defined and named (Braun and Clarke, 2006). Video audio and comment sections were analysed separately. As with the content analysis, the second coder validated all identified themes.

\section{Ethical Considerations}

The study received institutional approval and adhered to BPS guidelines for internetmediated research (2017). All YouTubers are allocated pseudonyms to protect anonymity. 


\section{Results}

\section{Thematic Analysis: YouTube Video Audio}

Thematic analysis of the audio from the selected videos revealed three themes 'Fitness and beauty', 'Trust me-I'm a YouTuber' and 'Health for the right reasons'. Themes and respective subthemes are presented in Figure 1. <<INSERT FIGURE 1 HERE >>

\section{Theme 1: Fitness as Beauty}

YouTubers presented fitness and physical appearance as synonymous through discussing how exercise could be tailored to change physical appearance and to meet specific appearance goals:

...by working in muscles in and around your boob areas you can actually improve the overall appearance of your chest.

(Grey 2, 14-17)

I do want a slim tiny waist and that big booty. That is my goal.

(Jessica 2, 49-53)

... take a progress photo, you're gonna check it every four weeks, you're going to compare

(Mandy 3, 20-22)

Instructions and recommendations relating to diet and exercise were with the intention of changing physical appearance or specific body parts. Using photographs of one's own body to assess physical changes highlights the cosmetic nature of fitness goals. This theme is divided into subthemes of 'I look good in muscles' and 'Demonisation of fat'.

Subtheme 1.a.: 'l look good in muscles' 
Concerning the nature of appearance-oriented fitness goals, YouTubers defined goals as the gain of visible musculature:

I was like oh my I got an 8 pack... That is the evolution of my body.

(Jessica 1, 130-132)

When YouTubers described their own fitness journeys, gaining visible muscle definition was the end goal. The idealisation of the presence of visible muscle was further established by negative association to a lack of visible muscle, prevalent in both male and female YouTubers:

I had no muscle definition, my belly was getting out of control.

(Ginger 1, 209-211)

The importance associated with presence or lack of muscles highlights this major theme of Fitness as beauty, and that a primary goal of fitness is appearance-related. A further nuance observed was that female YouTubers desired the appearance of visible, but strictly limited, muscle tone:

I had this mentality that if I lifted weights I was just going to get huge

(Mandy 1, 62-64)

A hyper-muscular appearance or being too "big" was seen as undesirable and unattractive. Hyper-muscularity was associated with body dissatisfaction in females and associated with bulk, but desirable for males.

Subtheme 1.b.: Demonisation of fat

Participants articulated the importance of fat loss, both through illustration of their personal success at fat loss, and through giving instruction on how to achieve this:

I follow a three-part system, overall fat loss, targeted muscle building, and then stubborn fat loss.

(Grey, 27-29) 
Fat loss was perceived as a motivator, a goal and a primary constituent of health and fitness, and achieved through methods such as calorie tracking:

The amount of calories you're consuming a day is very important

(Mike 2, 92-94)

The macros [nutrients] on them for two pieces are zero fat, zero protein, 17 grams of carbs, and 12 grams of sugar.

(Agatha 1, 103-105)

YouTubers gave advice to record calories and nutrition of all food and drink consumed as a means of self-monitoring to best facilitate fat loss.

\section{Theme 2: Trust me I'm a YouTuber}

This theme illustrates how YouTubers cultivate trust in viewers through sharing personal information. One such method of achieving this is the sharing of 'daily vlog' videos, where they film their daily activities talking directly to the viewer:

Hey guys, welcome to my bedroom, look I got a new bed ... remember how I was not going to sleep for a long time?

(Erika 1, 1-3)

Portraying daily activities and speaking directly to the viewer creates intimacy, as the viewer is indirectly participating in the YouTubers' activities. YouTubers address viewers as they would friends, even referring to details from previous content.

YouTubers addressed viewers by asking direct questions and encouraging engagement. YouTubers revealed both negative and positive personal stories about their past and current life, which were not necessarily always related to fitness:

... Sharing my story might help someone ... so this is my before and after story about my struggle with an eating disorder.

(Rosie and $\operatorname{Jim} 3,4-7$ ) 
This further facilitated intimacy in the host-user relationship. YouTubers often presented advice based on behaviours trialled on themselves:

... can I get abs after having a baby? Yes! ... I'm telling you because I'm sorry but I do have abs and I did have a baby so there you go, that's my proof.

(Serena 3, 35-37)

YouTubers legitimised diet and exercise advice by recounting their own experiences when trying to deal with a fitness-related issues and promoted the best solution that they utilised.

\section{Theme 3: 'Health for the right reasons'}

This theme explores where YouTubers conveyed a message of pursuing fitness for the sake of health:

I'm going to just work out because it makes me feel so good and I really actually enjoy doing it.

(Erika 1, 56-60)

In this theme, YouTubers emphasised goals related to fitness and health, not appearance. The importance of sustainability of a healthy lifestyle was also highlighted. The aforementioned was achieved through YouTubers recounting their own experiences and how they reached the conclusion that exercise and diet should be executed to feel good and for health, not for appearance:

I initially started my fitness journey because I was like 'ah I wanna loose a couple of pounds' but as I was eating healthier and working out ... I felt good, wasn't just felt like looking good but it was about feeling good.

(Jessica 1, 51-54) 


\section{Content Analysis: YouTube Video Imagery}

Of the 184 images obtained rom the videos, 145 images were of people. The sample consisted primarily of images of females (85\%). In terms of adiposity, $67 \%$ of images of females and $94 \%$ of images of males were classified as 'thin'. Predominant muscularity was visible at $36 \%$ for females and $59 \%$ for males. The majority of females were engaging in non-fitness related posing $(60 \%)$ and the males in fitness activities (53\%). Images of females mostly contained 'some degree of objectification' (37\%), whilst males mostly had no objectification (38\%). Table 2 depicts the number of occurrences of each code. For food, 39 images of food were coded, of which $79 \%$ were images of healthy foods and $21 \%$ of images were of unhealthy foods. <<INSERT TABLE 2 HERE >>

\section{Thematic Analysis: YouTube Video Comments}

Thematic analysis of the ten highest rated comments from each video revealed a single major theme, 'YouTube fitness community' and two subthemes, 'Body appearance dissatisfaction' and 'YouTuber fitness role models', with sub-patterns (see Figure 2). Commenters are allocated identification numbers.

<<INSERT FIGURE 2 HERE >>

\section{Theme 1: YouTube fitness community}

This theme encompasses how a sense of community was generated through the sharing of health and fitness advice within commenters. This involved conversations and debates about diet and exercise routines:

3.22: I never diet, I just cut out junk food.

3.24: How about sugar?

3.25: I decided to eat fast food not more than once in two months, and no soft/hard drinks ... I drink 4-5 litres of water everyday. 
3.26: too much water isn't good either.

(Erika 3, 97-103)

Commenters asked each other specific questions relating to diet, exercise and fitness motivation. Other commenters responded with advice based on their own experiences and knowledge, with the aim of helping each other clarify problems relating to diet and exercise. YouTubers also often became involved in the discussion by directly answering queries from commenters and initiated discussion by posing questions to viewers, with commenters responding accordingly:

1.26: Can anyone help me? I started squatting with just the bar ... I noticed my legs getting thicker ... is it possible to get a bigger butt while retaining nice long legs!?

Ginger.1: If you're going really low and your knees are coming out past your toes when you're at your lowest point in the squat you're working your quads more than your glutes.

(Ginger 1, 84-90)

This theme is divided into subthemes of 'Body appearance dissatisfaction' and 'YouTuber fitness role models'.

Subtheme 1.a.: Body appearance dissatisfaction This theme illustrates the frequent occurrence of commenters stating that they were unhappy with the appearance of their bodies or specific body parts:

3.17: ...I love my body but my legs.... I hate them...

(Grey 3, 44)

2.2: I workout two hours a days and I'm just never happy with my body :(

(Erika 2, 2) 
Expression of body dissatisfaction was accompanied with frustration that physical appearance remained unsatisfactory despite attempts to pursue fitness.

Commenters expressed a desire to change the appearance of specific body parts:

1.5: I want abs, my upper abs are improving but my lower abs aren't, as it makes my belly look bloated.

(Mike 1, 10-20)

Commenters illustrated their issues in detail and would seek advice on the subject from other commenters and/or the YouTuber. In addition to specific body part focus, and overall aim of weight loss was prevalent, with the aim of improving all over body appearance rather than health:

1.9: I lost $16 \mathrm{lbs}$ in two months ... I still need $10 \mathrm{lbs}$ to go but it's a start.

(Agatha 1, 17-22)

1.38: You helped me drop to 85 pounds!!!!!!!

1.39: Oh my God, congratulations!!

(Erika 1, 80-81)

Commenters described how they had achieved weight loss or were aspiring to lose weight. Successful weight loss was associated as a positive outcome of the diet or exercise regimes and was greeted with praise from other commenters and YouTubers. Conversely, weight loss goals not being met, either through failing to lose weight or not achieving a specific goal, was perceived as negative or associated with disappointment or a lack of fulfilment:

1.7: I've lost 5 pounds in 7 days and I'm a little disappointed. I thought I would lose more.

(Serena 1, 20-21) 


\section{Subtheme 2: YouTuber fitness role models}

Commenters expressed a high level of appreciation towards YouTubers for providing advice and support:

3.3: ...You're a role model, and a beacon of hope, Rosie. :)

(Rosie 3, 13-15)

1.8: ...you've been so influential and made a big impact on my starting journey thus far.

(Mandy 1, 23-26)

YouTubers fitness and appearance was perceived as aspirational. Commenters appreciated and were thankful for the information that YouTubers provided about fitness.

\section{Discussion}

Fitspiration content on YouTube portrays a dual image of health and fitness as a beauty aesthetic. The superficial focus of the fitness ideal was illustrated by the themes, 'Fitness as Beauty' 'I look good in muscles', 'Specific body part focus' and 'Body appearance dissatisfaction.' YouTubers focused on how behaviour change could lead to aesthetic change. Superficial changes included the achievement of visible musculature and altering the appearance of specific body parts, such as reducing waist size. This was reflected in commenters reiterating the appearancerelated nature of their fitness goals, and expressing frequent body dissatisfaction. This characterisation of the fitspiration movement reflects that found in previous research in which it outwardly endorses health promoting behaviours, but equates fitness to the achievement of an unrealistic beauty ideal (Tiggemann and Zaccardo, 2015, 2016). 
Performance of health behaviour to change physical appearance creates an understanding that in order to be fit, an individual's body must look a particular way. This was seen in the subtheme 'I look good in muscles', in which attaining visible muscle was a primary goal. However, for females, being hyper-muscular, appearing 'bulky', or 'too big' was also seen as unattractive and undesirable. This same desire for leanness seen in the thinspiration movement is again seen in the themes 'Demonisation of fat' and 'Weight loss-oriented goals,' in which YouTubers conveyed fat loss as an integral factor in achieving the desired fit aesthetic. Reflecting this, commenters were more satisfied with their progress if they achieved net weight loss. The glorification of overall weight loss suggests the idealisation of thinness remains, and is further communicated by the body shapes present in the videos. Content analysis revealed that the most common body shape was thin with visible muscularity, reiterating that fitspiration content is characterised by the appearance of a thin, lean body.

The idealisation of a thinness is concurrent with traditional media beauty ideals and, in particular, the thin ideal (Boepple and Thompson, 2016; D'Alessandro and Chitty, 2011). Thinspiration consisted of images of extreme thinness and promotion of extreme weight loss via food restriction and over-exercising (Chancellor et al., 2016), characterised by fat phobia (Dalley and Buunk, 2009; Woud et al., 2011). Whilst this study found that fitspiration content on YouTube does not idealise skeletal bodies or extreme weight loss, nor actively promotes such extreme health risk behaviours, fitspiration content did reward weight loss and thinness, demonstrating similarities with thinspiration. These conclusions emulate Talbot et al.'s (2017) findings that fitspiration content is less unhealthy than thinspiration, however, fitspiration similarly idealises thinness. As fat phobia is a key motivator for 
weight loss in thinspiration, it is possible that this explains the emphasis placed on fat and weight loss in fitspiration. This represents the divided definition of fitspiration; the promotion of health juxtaposed with the promotion of thinness (Tiggemann and Zaccardo, 2016).

The theme 'Demonisation of fat' demonstrates that YouTubers promote calorie restriction, elimination of food groups, and over-exercising for fat loss; behaviours comparable to those endorsed by the thinspiraiton movement and ones which may too be problematic for health. Restrictive calorie consumption is a recognised symptom of disordered eating (American Psychiatric Association, 2013). Commenters reported fasting and calorie tracking in response to YouTuber advice (see theme 'YouTube fitness community'), demonstrating that consumers have considered and performed problematic health behaviour on the basis of fitspiration content.

Content analysis revealed that physical beauty standards in fitspiration are consistent with the dominance of female images seen in thinspiration. The current study found $85 \%$ of images were of females, reflecting the findings of Tiggemann and Zaccardo (2016). Research has demonstrated that females who post fitspiration content are more likely to have a high internalised drive for thinness, presence of eating disorder symptomology, or diagnosis of an eating disorder (Boepple and Thompson, 2014; Holland and Tiggemann, 2017). Furthermore, consumers of fitspiration are more likely to be female and have a diagnosed eating disorder (Carrotte et al., 2015). This further demonstrates the similarities between thinspiration and fitspiration in terms of the associations with offline behaviour. This is particularly concerning for the YouTube social media platform, as YouTubers have a close relationship with their consumers, as seen in 'Trust me l'm a YouTuber,' 
'YouTuber fitness role models.' and 'YouTube fitness community'. Information promoted about health behaviours by YouTubers is legitimised by the level of trust achieved in the host-user relationship, providing consumers with confidence that following the information promoted in fitspiration content is legitimate. As this study and previous research has established that fitspiration content may promote negative health behaviours, this is concerning.

\section{Limitations}

In terms of design, a form of content analysis of video should be developed. Tiggemann and Zaccardo's (2016) coding structure was designed to analyse static images, thus there was difficulty with coding all imagery in the videos and some images were unable to be coded.

To understand the impact of fitspiration, it is crucial that more research is conducted to investigate the perceptions of fitspiration from consumers, particularly males. Fitspiration is primarily a female-oriented movement with a proclivity toward images of thin, toned females (Tiggemann and Zaccardo, 2016), and this is reflected in the data collected for the present study. However, the fitspiration movement also targets male consumers, though with very different, hyper-muscular imagery (Tiggemann and Zaccardo, 2016). It is important to further investigate how maleorientated fitspiration is interpreted by consumers so that suitable interventions can be developed to mitigate the harmful impact that fitspiration has on health.

\section{Conclusions}

Within fitspiration content on YouTube, health and fitness behaviours were performed to change physical appearance, and offered many similar images and messages as the banned thinspiration movement. This pursuit of a 'fit ideal' aesthetic was reflected in consumer comments, where body dissatisfaction was 
seen, and wherein problematic health behaviours were reported as being performed on the advice of YouTubers. The health-positive message of fitspiration appears to have been eclipsed by the implication that fitness is synonymous with thinness.

\section{References}

Abena (2013) From thinspo to fitspiration: How social media could be affecting your body image.

American Psychiatric Association (2013) Diagnostic and Statistical Manual of Mental Disorders (DSM-5®). American Psychiatric Pub.

Bandura A (1978) Social learning theory of aggression. Journal of Communication 28(3): 12-19.

Benton C and Karazsia BT (2015) The effect of thin and muscular images on women's body satisfaction. Body Image 13: 22-27. Available at: https://doi.org/10.1016/j.bodyim.2014.11.001.

Boepple L and Thompson JK (2014) A content analysis of healthy living blogs:

Evidence of content thematically consistent with dysfunctional eating attitudes and behaviors. International Journal of Eating Disorders 47(4). John Wiley \& Sons, Ltd: 362-367. DOI: 10.1002/eat.22244.

Boepple $L$ and Thompson JK (2016) A content analytic comparison of fitspiration and thinspiration websites. International Journal of Eating Disorders 49(1). John Wiley \& Sons, Ltd: 98-101. DOI: 10.1002/eat.22403.

Boyd DM and Ellison NB (2007) Social network sites: Definition, history, and scholarship. Journal of computer-mediated Communication 13(1). Wiley Online Library: 210-230.

Braun V and Clarke V (2006) Using thematic analysis in psychology. DOI: 10.1191/1478088706qp063oa. 
British Psychological Society (2017) Ethics Guidelines for Internet-mediated Research. INF206/04.2017. Available at: www.bps.org.uk/publications/policyand-guidelines/ research-guidelines-policy-documents/researchguidelines-poli.

Cafri G, Yamamiya Y, Brannick M, et al. (2005) The Influence of Sociocultural Factors on Body Image: A Meta-Analysis. Clinical Psychology: Science and Practice 12(4). John Wiley \& Sons, Ltd (10.1111): 421-433. DOI: 10.1093/clipsy.bpi053.

Carrotte ER, Vella AM and Lim MSC (2015) Predictors of 'Liking' Three Types of Health and Fitness-Related Content on Social Media: A Cross-Sectional Study. Journal of medical Internet research. Centre for Population Health, Burnet Institute, Melbourne, Australia. elise.carrotte@burnet.edu.au. DOI: 10.2196/jmir.4803.

Chancellor S, Pater JA, Clear T, et al. (2016) \#thyghgapp: Instagram content moderation and lexical variation in pro-eating disorder communities.

Proceedings of the 19th ACM Conference on Computer-Supported Cooperative Work \& Social Computing: 1201-1213.

Chau C (2010) YouTube as a participatory culture. New Directions for Youth Development 2010(128). John Wiley \& Sons, Ltd: 65-74. DOI: 10.1002/yd.376. Cohen R and Blaszczynski A (2015) Comparative effects of Facebook and conventional media on body image dissatisfaction. Journal of Eating Disorders 3(1): 23. DOI: 10.1186/s40337-015-0061-3.

Cramblitt B and Pritchard M (2013) Media's influence on the drive for muscularity in undergraduates. Eating Behaviors 14(4): 441-446. DOI:

https://doi.org/10.1016/j.eatbeh.2013.08.003.

D'Alessandro S and Chitty B (2011) Real or relevant beauty? Body shape and 
endorser effects on brand attitude and body image. Psychology \& Marketing 28(8). John Wiley \& Sons, Ltd: 843-878. DOI: 10.1002/mar.20415.

Dalley SE and Buunk AP (2009) 'Thinspiration' vs. 'fear of fat'. Using prototypes to predict frequent weight-loss dieting in females. Appetite 52(1): 217-221. DOI: https://doi.org/10.1016/j.appet.2008.09.019.

Dittmar H and Howard S (2004) Thin-ideal internalization and social comparison tendency as moderators of media models' impact on women's body-focused anxiety. Journal of Social and Clinical Psychology 23(6). Guilford Press: 768791.

Eisenberg ME, Ward E, Linde JA, et al. (2017) Exposure to teasing on popular television shows and associations with adolescent body satisfaction. Journal of Psychosomatic Research 103: 15-21. DOI: https://doi.org/10.1016/j.jpsychores.2017.09.014.

Eyal K and Te'eni-Harari T (2013) Explaining the Relationship Between Media Exposure and Early Adolescents' Body Image Perceptions. Journal of Media Psychology 25(3). Hogrefe Publishing: 129-141. DOI: 10.1027/18641105/a000094.

Fardouly J and Vartanian LR (2016) Social Media and Body Image Concerns: Current Research and Future Directions. Current Opinion in Psychology 9: 1-5. DOI: https://doi.org/10.1016/j.copsyc.2015.09.005.

Flament MF, Hill EM, Buchholz A, et al. (2012) Internalization of the thin and muscular body ideal and disordered eating in adolescence: The mediation effects of body esteem. Body Image 9(1): 68-75. DOI: https://doi.org/10.1016/j.bodyim.2011.07.007.

Galioto R and Crowther JH (2013) The effects of exposure to slender and muscular 
images on male body dissatisfaction. Body Image 10(4): 566-573. DOI:

https://doi.org/10.1016/j.bodyim.2013.07.009.

Ghaznavi J and Taylor LD (2015) Bones, body parts, and sex appeal: An analysis of \#thinspiration images on popular social media. Body Image 14: 54-61. DOI: https://doi.org/10.1016/j.bodyim.2015.03.006.

Hanson G (2009) Social Interaction and Co-Viewing With YouTube: Blending Mass Communication Reception and Social Connection AU - Haridakis, Paul. Journal of Broadcasting \& Electronic Media 53(2). Routledge: 317-335. DOI:

10.1080/08838150902908270.

Harrison K (2000) Television Viewing, Fat Stereotyping, Body Shape Standards, and Eating Disorder Symptomatology in Grade School Children. Communication Research 27(5). SAGE Publications Inc: 617-640. DOI:

$10.1177 / 009365000027005003$.

Harrison K (2003) Television Viewers' Ideal Body Proportions: The Case of the Curvaceously Thin Woman. Sex Roles 48(5): 255-264. DOI:

10.1023/A:1022825421647.

Hausenblas HA, Campbell A, Menzel JE, et al. (2013) Media effects of experimental presentation of the ideal physique on eating disorder symptoms: A metaanalysis of laboratory studies. Clinical Psychology Review 33(1): 168-181. DOI: https://doi.org/10.1016/j.cpr.2012.10.011.

Holland G and Tiggemann M (2016) A systematic review of the impact of the use of social networking sites on body image and disordered eating outcomes. Body Image 17: 100-110. DOI: https://doi.org/10.1016/j.bodyim.2016.02.008.

Holland G and Tiggemann M (2017) 'Strong beats skinny every time': Disordered eating and compulsive exercise in women who post fitspiration on Instagram. 
International Journal of Eating Disorders 50(1). John Wiley \& Sons, Ltd: 76-79. DOI: 10.1002/eat.22559.

Judkis M (2012) Instagram bans 'Thinspiration,' pro-eating disorder images.

Available at: https://www.washingtonpost.com/blogs/arts-post/post/instagrambans-thinspiration-pro-eating-disorderimages/2012/04/24/gIQAXLeaeT_blog.html?noredirect=on\&s\&utm_term=.20f65 ca590db (accessed 2 September 2018).

Khan ML (2017) Social media engagement: What motivates user participation and consumption on YouTube? Computers in Human Behavior 66: 236-247. DOI: https://doi.org/10.1016/j.chb.2016.09.024.

Knobloch-Westerwick S (2015) Thinspiration: Self-Improvement Versus SelfEvaluation Social Comparisons with Thin-Ideal Media Portrayals. Health Communication 30(11). Routledge: 1089-1101. DOI:

10.1080/10410236.2014.921270.

Lehman-Wilzig S and Cohen-Avigdor N (2004) The natural life cycle of new media evolution: Inter-media struggle for survival in the internet age. New Media \& Society 6(6). SAGE Publications: 707-730. DOI: 10.1177/146144804042524.

McLean SA, Paxton SJ, Wertheim EH, et al. (2015) Selfies and social media: relationships between self-image editing and photo-investment and body dissatisfaction and dietary restraint. Journal of Eating Disorders 3(1): O21. DOI: 10.1186/2050-2974-3-S1-O21.

Myers TA and Crowther JH (2009) Social comparison as a predictor of body dissatisfaction: A meta-analytic review. Journal of abnormal psychology 118(4). American Psychological Association: 683.

O'Keeffe GS and Clarke-Pearson K (2011) The impact of social media on children, 
adolescents, and families. Pediatrics 127(4). Am Acad Pediatrics: 800-804.

Perloff RM (2014) Social Media Effects on Young Women's Body Image Concerns:

Theoretical Perspectives and an Agenda for Research. Sex Roles 71(11): 363377. DOI: 10.1007/s11199-014-0384-6.

Robinson L, Prichard I, Nikolaidis A, et al. (2017) Idealised media images: The effect of fitspiration imagery on body satisfaction and exercise behaviour. Body Image 22: 65-71. DOI: https://doi.org/10.1016/j.bodyim.2017.06.001.

Santarossa S, Coyne P, Lisinski C, et al. (2016) \#fitspo on Instagram: A mixedmethods approach using Netlytic and photo analysis, uncovering the online discussion and author/image characteristics. Journal of Health Psychology. SAGE Publications Ltd: 1359105316676334 . DOI: 10.1177/1359105316676334.

Sidani JE, Shensa A, Hoffman B, et al. (2016) The Association between Social Media Use and Eating Concerns among US Young Adults. Journal of the Academy of Nutrition and Dietetics 116(9): 1465-1472. DOI: https://doi.org/10.1016/j.jand.2016.03.021.

Slater A, Varsani N and Diedrichs PC (2017) \# fitspo or\# loveyourself? The impact of fitspiration and self-compassion Instagram images on women's body image, self-compassion, and mood. Body Image 22. Elsevier: 87-96.

Talbot CV, Gavin J, van Steen T, et al. (2017) A content analysis of thinspiration, fitspiration, and bonespiration imagery on social media. Journal of Eating Disorders 5(1): 40. DOI: 10.1186/s40337-017-0170-2.

Tiggemann M and Slater A (2004) Thin ideals in music television: A source of social comparison and body dissatisfaction. International Journal of Eating Disorders 35(1). Wiley Online Library: 48-58.

Tiggemann M and Zaccardo M (2015) 'Exercise to be fit, not skinny': The effect of 
fitspiration imagery on women's body image. Body Image 15: 61-67. DOI: https://doi.org/10.1016/j.bodyim.2015.06.003.

Tiggemann M and Zaccardo M (2016) 'Strong is the new skinny': A content analysis of \#fitspiration images on Instagram. Journal of Health Psychology 23(8). SAGE Publications Ltd: 1003-1011. DOI: 10.1177/1359105316639436.

Tolson A (2010) A new authenticity? Communicative practices on YouTube. Critical Discourse Studies 7(4). Routledge: 277-289. DOI:

10.1080/17405904.2010.511834.

Wick MR and Harriger JA (2018) A content analysis of thinspiration images and text posts on Tumblr. Body Image 24: 13-16. DOI:

https://doi.org/10.1016/j.bodyim.2017.11.005.

Woud ML, Anschutz DJ, Van Strien T, et al. (2011) Measuring thinspiration and fear of fat indirectly. A matter of approach and avoidance. Appetite 56(2): 451-455. DOI: https://doi.org/10.1016/j.appet.2010.12.012.

YouTube (2018) Fitness. Available at: https://www.youtube.com/results?search_query=fitness\&sp=EgIQAkIECAESAA \%253D\%253D. 
Table 1. Pseudonyms of channel hosts, channel subscriber count and summary of channel content.

\begin{tabular}{|c|c|c|c|}
\hline Pseudonym & Subscribers $n$ & Gender & Content \\
\hline Rosie and Jim & $4,428,956$ & $\begin{array}{l}\text { Female \& } \\
\text { Male }\end{array}$ & $\begin{array}{l}\text { Fitness couple dedicated } \\
\text { to providing free } \\
\text { instructional work out } \\
\text { videos and workout plans } \\
\text { for a variety of fitness } \\
\text { levels. }\end{array}$ \\
\hline Erika & $3,909,691$ & Female & $\begin{array}{l}\text { A Pilates-oriented work } \\
\text { out and lifestyle channel. }\end{array}$ \\
\hline Mike & $1,647,817$ & Male & $\begin{array}{l}\text { Male-oriented body } \\
\text { building instructional and } \\
\text { advice videos. }\end{array}$ \\
\hline Mandy & 787,068 & Female & $\begin{array}{l}\text { Fitness, lifestyle and } \\
\text { exercise daily vlogs. }\end{array}$ \\
\hline Jessica & 551,802 & Female & $\begin{array}{l}\text { Fitness daily vlogs, } \\
\text { exercise-gym instructor. }\end{array}$ \\
\hline Ginger & 503,995 & Female & $\begin{array}{l}\text { Health and fitness trainer, } \\
\text { body type diet and } \\
\text { exercise. }\end{array}$ \\
\hline Grey & 501,202 & Female & $\begin{array}{l}\text { Women's exercise- } \\
\text { science instructor and } \\
\text { advisor. }\end{array}$ \\
\hline
\end{tabular}




\begin{tabular}{|c|c|c|c|}
\hline Tim & 428,977 & Male & $\begin{array}{l}\text { Fitness challenge } \\
\text { vlogger, fitness lifestyle, } \\
\text { body building instructional } \\
\text { videos. }\end{array}$ \\
\hline Serena & 261,778 & Female & $\begin{array}{l}\text { Fitness inspiration, fit } \\
\text { mom, exercise and diet } \\
\text { advice for women. }\end{array}$ \\
\hline Agatha & 118,756 & Female & $\begin{array}{l}\text { Fitness competition } \\
\text { contestant, fitness } \\
\text { vlogger, fitness instructor. }\end{array}$ \\
\hline
\end{tabular}


Table 2. Adiposity type, degree of muscularity, type of action and extent of objectification according to gender.

\begin{tabular}{|c|c|c|c|}
\hline & & Women & Men \\
\hline \multirow[t]{3}{*}{ Adiposity, n (\%) } & Thin & $115(67)$ & $30(94)$ \\
\hline & Average & $58(33)$ & $2(6)$ \\
\hline & Overweight & $0(0)$ & $0(0)$ \\
\hline \multirow[t]{4}{*}{ Muscularity, n (\%) } & Little to none & $51(29)$ & $0(0)$ \\
\hline & Visible & $63(36)$ & $19(59)$ \\
\hline & High level & $14(8)$ & $7(22)$ \\
\hline & Unable to Determine & $45(26)$ & $6(19)$ \\
\hline \multirow[t]{3}{*}{ Actions, n (\%) } & Posing (non-fitness related) & $104(60)$ & $15(47)$ \\
\hline & Fitness modelling & $7(4)$ & $0(0)$ \\
\hline & Engaging in fitness activity & $62(36)$ & $17(53)$ \\
\hline \multirow[t]{6}{*}{ Objectification, n (\%) } & Some degree of & $64(37)$ & $10(31)$ \\
\hline & objectification & & \\
\hline & Body part main focus & $24(14)$ & $3(9)$ \\
\hline & Sexually suggestive & $22(13)$ & $4(13)$ \\
\hline & Absence of head/face & $20(11)$ & $3(9)$ \\
\hline & None & $43(25)$ & $12(38)$ \\
\hline
\end{tabular}




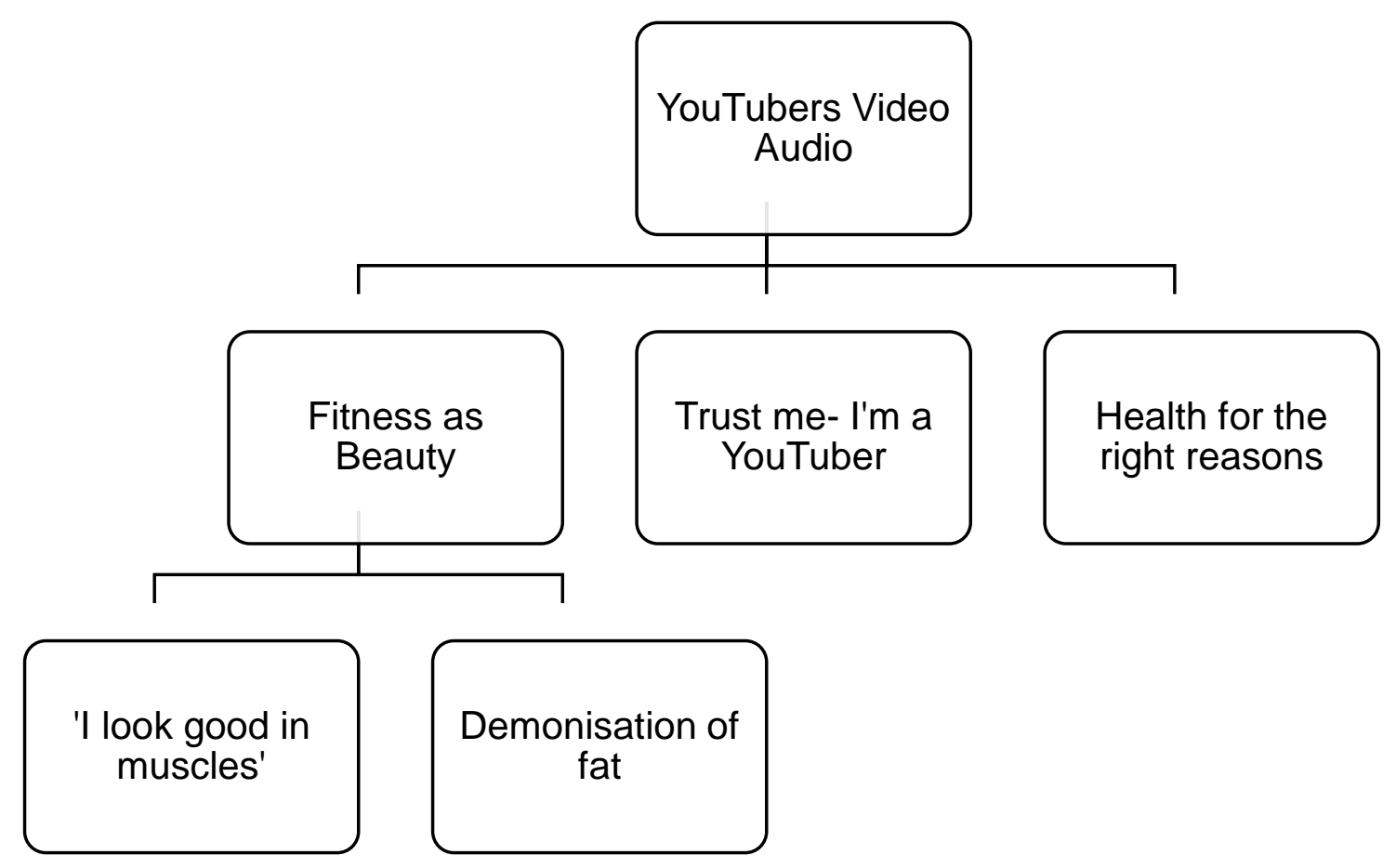

Figure 1. Thematic map of themes and subthemes from YouTube video audio. 

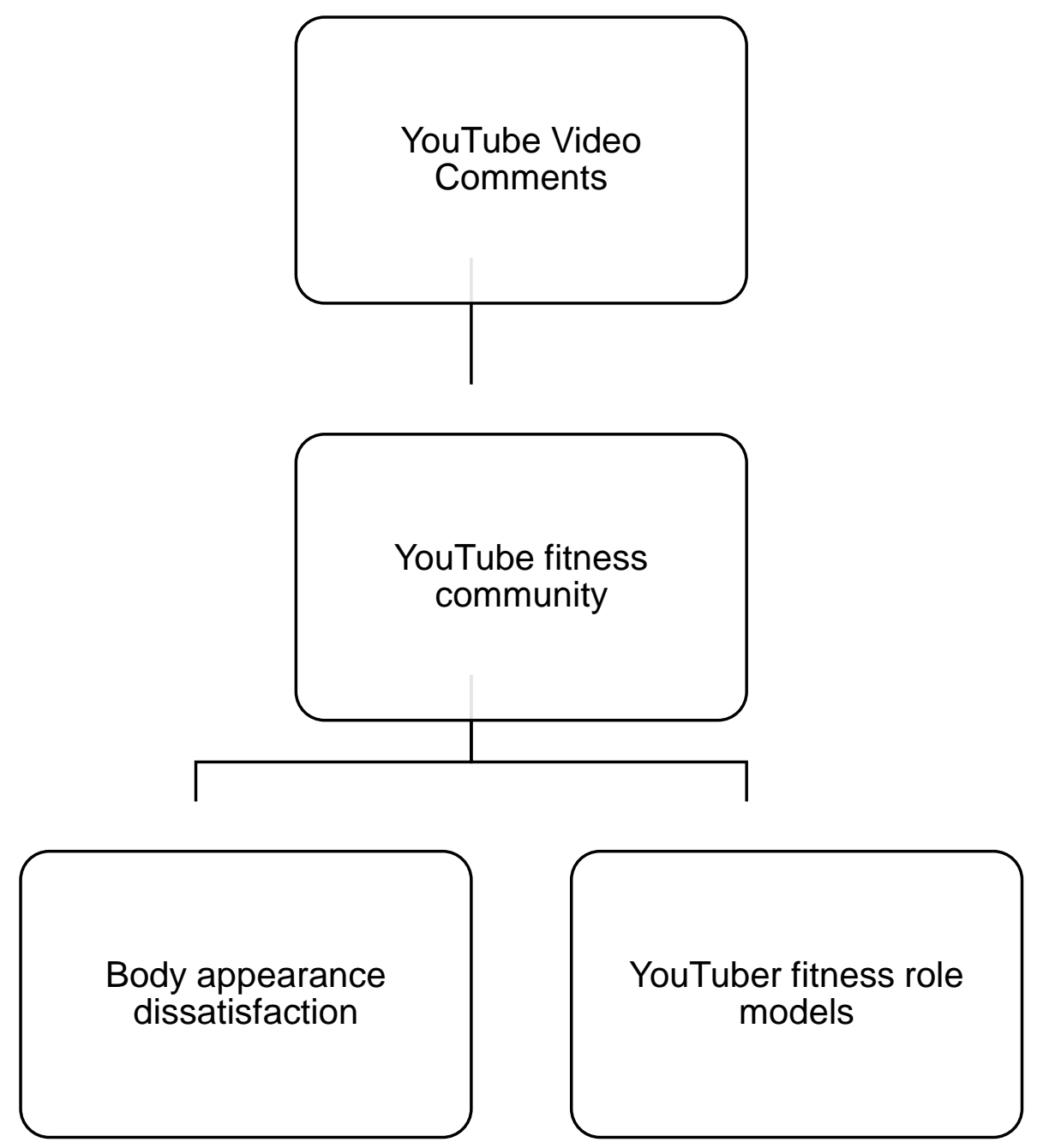

Figure 2. Thematic map of themes and subthemes from YouTube video comments. 